\title{
Assessing 'Quality': The unfolding of the 'Good'-Collective decision making in juries of urban design competitions
}

\author{
Joris E. Van Wezemael ${ }^{*}$, Jan M. Silberberger, Sofia Paisiou
}

Human Geography, University of Fribourg, Switzerland

\begin{abstract}
Summary The radical orientation towards the future; the notion of novelty, experimentation and creativity makes an architectural competition a fascinating object - not least for management studies. In the paper at hand we discuss findings of an ethnographic study on the jury assessment sessions of four recent architectural competitions in Switzerland. We consider these meetings as a laboratory from which we might gain a better understanding of collective decision making processes in general, that is, beyond the scope of design competitions.

We point out that the relevant criteria for assessment of architectural propositions are not given in advance; rather they emerge during, that is, through the jury's decision making process: while the board of jurors explores the space of potential solutions as generated by the submitted architectural propositions. Therefore, we believe that a competition jury's decision making (or sense making) process tells us a lot about dealing with complex situations. Situations that do not just display a variety of actors (humans and non-humans) but in particular a high degree of intertwining of the involved actors.
\end{abstract}

There is no person wise enough to tackle and understand all the systems and their interconnections in order to address a certain situation. (Boland \& Collopy, 2004)

\section{Introduction}

Their radical orientation towards the future; the notion of novelty, experimentation and creation/creativity they carry; their staging of uncertainty; and the co-evolution of the

\footnotetext{
* Corresponding author at: Department of Geosciences, University of Fribourg, 4, chemin du Musée, $\mathrm{CH}-1700$ Fribourg, Switzerland. Tel.: +412630092 55; fax: +41263009746.

E-mail address: joris.vanwezemael@unifr.ch (J.E. Van Wezemael).
}

criteria to judge with the unfolding of what will be judged (and thus the centre stage of uncertainty and not knowing) that they imply make design competitions a fascinating object - not least for management studies. In the article at hand we put the focus on the sense and decision making processes performed by the jury of an architectural competition. We are aware of the fact that this can be regarded as an entry-point to a much wider process in the sense that the jury assessment sessions of an architectural competition can be regarded as a laboratory from which we might gain a better understanding of collective decision making processes in general. We claim that the jury deliberations of an architectural competition constitute a 'site' where diverse forms of reality are folded, hence: a very dense knot of mental, material and spoken relational networks. In what follows we will argue that the act of modulating singularities does not 
have to be considered as a weakness or failure since it may (as in the case we will present) be a 'proof of excellence' of the decision makers' work.

In order to do so we will use the remaining space of this introduction to describe an essential characteristic of architectural competitions, to relate the conception of enduring heterogeneity from knowledge studies to jury assessment sessions and to sketch out our empirical research design. In the second part of the paper we will introduce key concepts for complexity thinking. In the third part we will present a sequence of four observations by means of which we will follow a controversially discussed architectural project through three days of jury assessment sessions. Then, in part four, we will revisit our four observations by means of conceptualising the decision making process as what we will call a modulation of singularities.

\section{A first essential characteristic of an architectural competition}

We view the process of opening up (being liquid and flexible for the production of a variety of ideas) and then narrowing down (the crystallisation process, that is, the jury determining a solution out of the multitude of ideas, which is then actualised into another fixed set of materials) as the essential realm of architectural competitions. At the outset of each architectural competition, a given, actual site is opened up towards a virtual space of potential. Then its potential becomings are individuated into representations (projects submitted by the competing architecture offices), which are then - in the jury assessment session - contested on the basis of economic relations, statics and material properties, power relations among the networks which are folded together by the jury members, design paradigms, political struggles and so on. The jury assessment moves step by step towards a new possible actualisation of a place: the jury separates out potential solutions until only one remains, which then is going to manifest the site's future ${ }^{1}$ (Van Wezemael, 2010). Hence jury assessment sessions refer to both, what is actualised and what remains virtual. In this respect we propose to view jury assessment sessions as a 'site' where singularities that shape the jury's decision making are modulated and eventually actualised.

\section{Enduring heterogeneity}

In studies of 'learning environments' it is suggested that the concept of enduring heterogeneity keeps processes away from being locked into one single basin of attraction. Organisation science and studies on knowledge-creation show that there are conditions that are more likely to trigger the emergence of new forms (organisational solutions, designs, technical innovations) than others (Chia, 1997; Gibbons et al., 1994; Grabher \& Maintz, 2006; Kamoche \& Cunha, 2004; Nonaka \& Konno, 1998; Schön, 1995; Senge, 1990; Tsoukas \& Chia, 2002). As Van Wezemael (2008a) suggests

\footnotetext{
${ }^{1}$ Be there 7, 17 or 77 contributions to a design competition - they illustrate that we could solve an urban situation differently (Kohoutek, 2005).
}

"we can learn from the analysis of project ecologies (Grabher, 2004), geographies of knowledge-creation (lbert, 2007), or from science and technology studies (Latour, 1987), [that] learning processes are fuelled by the connection of heterogeneous elements (practices which belong to different places or to different projects or organizations) and - given a learning environment - from the encounter with novel and unexpected processes or 'anomalies'."

If we apply this argument to architectural competitions and in particular to juries in architectural competitions that means that the soundness of the jury's work (and to a large extent the soundness of the whole competition procedure) significantly relies on the heterogeneity of the perspectives of the jury members and therefore on the diversity of their knowings (Ibert, 2007; Van Wezemael, 2008b; Silberberger, Van Wezemael, Paisiou, \& Strebel, 2010). As Gilbert and Jormakka (2005) explain, it is common practice that a jury be composed of a group of individuals who represent a certain spectrum of professional views, interests and inclinations that populate the vocation. It is generally thought that the heterogeneity of positions will at least in part balance an extreme reaction to a project by any one particular jury member.

Our research strategy conceptually draws on a DeLandian inspired framework (Van Wezemael, 2010) which combines the ontology of assemblage theory (DeLanda, 2006) with concepts of complexity thinking. On this basis we conducted an ethnographic study of jury assessment sessions of four recent architectural competitions in Switzerland (see Table 1) in order to open the black box "jury assessment session", that is, to describe the internal complexity of a jury assessment session instead of focusing on its inputs (the submitted contributions) and/or its outputs (the contribution's ranking and the jury's statement of grounds). Methodically our ethnographic study draws on the work of Latour and Woolgar (1979), Latour and Yaneva (2008) and Yaneva (2009). ${ }^{2}$

\section{Key concepts for complexity thinking}

\section{The exteriority of relations}

Assemblage theory (DeLanda, 2006) replaces relations of interiority with relations of exteriority. While relations of interiority imply that "the component parts are constituted by the very relations they have to other parts in the whole" and the whole in turn "possesses an inextricable unity in which there is a strict reciprocal determination between parts" (DeLanda, 2006, p. 9), the exteriority of relations implies "a certain autonomy for the terms they relate" (DeLanda, 2006, p. 11). Hence, a part detached from a whole represented by relations of interiority "ceases to be what it

\footnotetext{
${ }^{2}$ Latour and Woolgar have observed scientists working in a biochemical laboratory. Over the period of two years Latour occupied an office within the laboratory and examined how scientists perform the construction of scientific facts. Yaneva studied the work of architects at the office of Rem Koolhaas by observing how architects proceed when designing a building. In the same spirit we observed how juries in architectural competitions produce their decisions by attending their sessions.
} 
Table 1 Basic facts of the four observed architectural competitions.

\begin{tabular}{|c|c|c|c|c|}
\hline & BASEL & ZURICH & WINTERTHUR & BERNE \\
\hline Task & $\begin{array}{l}\text { Extension to the Basel } \\
\text { Kunstmuseum }\end{array}$ & & Apartment com & \\
\hline Project Budget & 100 Mio. CHF (68 Mio. EUR) & $\begin{array}{l}50 \text { Mio. CHF } \\
\text { (34 Mio. EUR) }\end{array}$ & $\begin{array}{l}54 \text { Mio. CHF } \\
\text { (37 Mio. EUR) }\end{array}$ & \multirow{3}{*}{$\begin{array}{l}35 \text { Mio. CHF } \\
\text { ( } 24 \text { Mio. EUR) } \\
\text { One-stage, } \\
\text { Anonymous, open } \\
\text { Private }\end{array}$} \\
\hline Competition Type & \multicolumn{3}{|c|}{ Two-stage, Anonymous, selective procedure } & \\
\hline Client & Public & $\begin{array}{l}2 / 3 \text { Public, } \\
1 / 3 \text { Private }\end{array}$ & Public & \\
\hline
\end{tabular}

is, since being this particular part is one of its constitutive properties" (DeLanda, 2006, p. 9) whereas, in contradiction, a component part of a whole characterized by relations of exteriority (an assemblage) "may be detached from it and plugged into a different assemblage in which its interactions are different" (DeLanda, 2006, p. 10). Furthermore, relations of exteriority imply that "the properties of the component parts can never explain the relations which constitute a whole," although these relations "may be caused by the exercise of a component's capacities" (DeLanda, 2006, p. 11). In fact, the reason why the properties of an assemblage "cannot be reduced to those of its parts is that they are the result not of an aggregation of the components' own properties but of the actual exercise of their capacities" (DeLanda, 2006, p. 11). Now these capacities in turn "do depend on a component's properties but cannot be reduced to them since they involve reference to the properties of other interacting entities" (DeLanda, 2006, p. 11). So to speak, the execution of a given component's capacities involves an act of conspiracy between the given component and other components. Thus, the concept of the exteriority of relations on the one hand guarantees "that assemblages may be taken apart" while simultaneously "allowing that the interactions between parts may result in a true synthesis" (DeLanda, 2006, p. 11).

\section{Singularities}

Assemblages are not only an actual formation, they are also a virtual one due to the fact that the structure of the processes of assembly is not actual but virtual. Therefore an assemblage is not just characterized by its actual properties but also by what Deleuze refers to as a diagram: "a set of universal singularities (...) that would structure the space of possibilities associated with the assemblage" (DeLanda, 2006, p. 30). To elaborate, "analysis in assemblage theory is not conceptual but causal, concerned with the discovery of the actual mechanisms operating at a given spatial scale" whereas "the topological structure defining the diagram of an assemblage is not actual but virtual and mechanismindependent, capable of being realized in a variety of actual mechanisms, so it demands a different form of analysis" (DeLanda, 2006, p. 31).

Hence, assemblages consist of a field of actualities (exercised properties), a field of virtuality (potential properties), and a generative field: the intensive, individuating level. Singularities are virtual, but they are individuated in assem- blages, and so they are vital to the operation of those assemblages (Deleuze \& Guattari, 1987, p. 100). A singularity can act as an attractor and can therefore be understood as an un-actualised tendency (DeLanda, 2002, p. 71).

\section{A sequence of four 'constructed' observations}

Below we present a so-called 'vignette'. The term vignette is used in ethnography to describe short, completed sequences. A vignette is not to be mistaken for a transcription (e.g. of a tape recording). It is in fact a reconstruction of a situation based on field notes. In that manner a vignette can be regarded as an adequate tool providing a clear and vivid description of the problem at hand. The way we understand our vignette is borrowed from Söderström (2000). Söderström considers his vignettes to be wellunderstood fabrications and selections of his observations without the intention of "objectively" reproducing the observed situations.

Thus the following four extracts are not mere representations of something that actually happened. They should be read as a sequence of four 'constructed' observations, that is, four 'models' created on the basis of our field notes. The reason for 'constructing' these observations is twofold: firstly, we ensured absolute anonymity for the jury members and also guaranteed to make the architectural projects anonymous. Secondly, we intend to make statements of a more general sort (statements about decision-making as modulation of singularities) and not statements concerning a specific competition, specific architectural projects or specific jury members.

The move from actual observations to constructed ones can also be related to the Deleuzian diagram, that is, to diagrammatic thinking. The vignette displays an actual situation, an assemblage of various exercised properties. Some of these exercised properties are different to the ones noted in our field journal. Still, the assemblage displayed in the vignette and the assemblages described in our field journal represent analogical settings. In this sense we can regard our vignette as a 'model', a description of not just one specific actualisation but one that is valid or fit for a whole range of actualisations. Creating a vignette (or model) therefore requires to take a step back, that is, to focus not only on the field of actualities but also on the field of virtuality and the intensive level in order to identify patterns that ensure analogical performances on the actual level. 


\section{Vignette}

By means of the sequence of observations below we will follow a controversially discussed architectural proposition ("project three") through three days of jury assessment sessions. A football club has decided to build a new stadium for approximately 60,000 spectators right in the city's centre.

Observation 1. October 8th 2009, first day, first round of the jury assessment session of an architectural competition concerning the construction of a football stadium, ca. $10.30 \mathrm{am}$. The jury discusses the third project. Projects one and two have been eliminated quickly and almost without a dissentient vote. This seems to be the case, too, for project three. Several jurors object to the facade that project three proposes. Most jurors do so in a rather rigorous manner. Another three jurors regard the opening in the uppermost tier on the south side of the stadium as a fundamental weakness: "The club wants to have a boiling pot. And not something like an open air theatre." Only one juror tries to defend the project. He points out that the opening in the top tier also has its merits: "If you have ever owned a season-ticket you will know that not every match captivates your attention for the whole $90 \mathrm{~min}$ utes. There are more than enough games during which you would be happy about having the opportunity to watch something more interesting, like our beautiful city." However, soon he stops his rather half-hearted attempt to defend the project. His consideration trickles away. Without further discussion the jury eliminates project three.

Observation 2. October 9th 2009, second day of the jury assessment session, ca. $8.30 \mathrm{am}$. Before they start with the second round the jurors review their work of the previous day. While discussing the decisions they had made one of the jury members makes the motion to take project three back into the competition: "It is the only convincing project proposing no completely closed stadium. Probably we want to have that position still represented in our second jury session. Maybe we need that position in order to sharpen our evaluation and assessment criteria. But maybe we should really reconsider this position. This architect creates a relation between his stadium and the city." The juror who slightly defended project three on the first day immediately supports this motion. After only a brief discussion the jury accepts it.

Observation 3. October 9th 2009, second round, ca. $4.45 \mathrm{pm}$. The jury reaches project three, today's last project (due to reverse order). The jury president opens the discussion. He points out that project three is the only one left that suggests a stadium with an opening in the tier. Hereupon several jurors mark the missing third tier of the southern stand as a "disruption" and as a "no-go". Then the juror who made the motion in the morning speaks. He identifies the opening as a pivotal achievement: "Project three creates a view - a visual relation to the city. It generates a connection." Another juror supports him: "If you nowadays build a football stadium it is usually located on greenfield site. But in a case like ours where the site is located in the middle of the city, you have to take that as a subject." Soon more jurors share this perception. The jury is divided into two groups of almost the same size. One group fights the "window" in the southern stand: "That hole kills the atmosphere. The spirit escapes from in the stadium." The other group regards the opening as an essential contribution. However both groups agree that project three needs to improve with regard to its outside appearance. The two camps stay divided. Finally the jury president asks the jury members to vote for or against taking project three to the next round. The result of that voting is six against six. The jury president's vote eventually turns the balance and project three is taken to round three.

Observation 4. October 23rd 2009, third day of the jury assessment session, ca. $1 \mathrm{pm}$, in the middle of the third round. While project three had split the jury into two equally sized camps on the second day of the jury assessment session, this balance now gets destabilised. The alliance that was arguing against project three takes back both its main arguments. The contra-project-threealliance can be convinced that an opening of the uppermost tier is not to be regarded as a severe reduction with regard to the atmosphere in the stadium. Quite the opposite, there is now a common perspective that the opening implicates advantages regarding the mood in the stadium: "Maybe one does not have to keep the level of suspense permanently high by architectural means." The second main argument against project three, the not particularly thrilling outward appearance, still lasts. Nevertheless the jury is now convinced that this defect could be easily remedied. Naturally project three is invited to the competition's next and last stage, where there is only one other competitor (a project proposing a completely closed stadium) remaining.

\section{Decision making as modulation of singularities}

If we take a look at our first observation we can clearly identify a singularity: the so-called "boiling pot". The "boiling pot" as an idea obviously belongs to the virtual field. It has already been actualised in a number of football stadiums around the world "Anfield Road" in Liverpool, "Old Trafford" in Manchester) but has to be regarded as an un- 
actualised tendency at this point in our competition. The singularity "boiling pot" comprises mainly three characteristics: The stadium should be narrow, its tiers should be steep and covered by a roof. The "boiling pot" acts as a critical point. It plays the role of a template against which all propositions are measured. If a project shows a high degree of concordance it is assessed as a valuable solution, whereas a project that does not match the template is rejected. Exactly the latter is what happened to "project three" in Observation 1.

In what follows we will describe how this singularity, that is, the seemingly robust attractor "boiling pot" is modulated during the jury's decision making. Within the second observation we witness two trends. The first one uses "project three" merely as a tool in order to sharpen the evaluation and assessment criteria. By means of this trend the singularity "boiling pot" is left untouched if not to say supported. In this way the prior evaluation of "project three" and every negative aspect attached to it can stay valid and yet a door is opened to get the already excluded project back into the competition. Moreover this course of action has to be viewed with regard to the jury having to produce a stable final report displaying a convincing statement of grounds. The second trend, however, suggests a slight modulation of the singularity "boiling pot". By pointing out the unique quality of "project three", namely that it establishes a relation between the spectator in the stadium and the surrounding city through the opening in the uppermost tier, the "boiling pot" singularity is attacked indirectly. That is, it is not explicitly challenged. Rather the implications entailed by a positive appraisal of connecting the spectator to the city (the stadium somehow has to be opened up) are simply discounted.

In Observation 3 the jury becomes aware of the fact that two of their main requests ("boiling pot" and spectator-city connection) are mutually exclusive. This circumstance is mirrored in the jury's splitting into two camps of exactly the same size. The formerly dissenting position with regard to the singularity "boiling pot" managed to create a situation of instability: Half of the jurors try to keep the singularity "boiling pot" (the way it is), the other half tries to add a "negative" feature to the singularity's existing set. Namely that the aspect of closeness obviates connecting the inside of the stadium to the surrounding city. Still the same aspect of closeness keeps functioning positively in the sense that it generates the desirable dense atmosphere.

Observation 4 then shows us how a second "negative" feature is added to the list defining the singularity "boiling pot" or, put differently, how the singularity is further modulated. While the jurors in the beginning of the assessment session were clearly looking for an architecture that creates a dense, heatedly atmosphere on its inside and therefore immediately separated out "project three" that does not propose a completely closed stadium, they now have serious doubts with regard to the characteristic "closeness". A closed stadium, the jurors are now convinced, does not just make a connection between the spectators and the surrounding city impossible, it may also inflame the inside atmosphere unnecessarily to an inadequate level.

The sequence of the four observations depicts how the singularity "boiling pot" is modulated. In the beginning that singularity disposes a strong internal cohesion. It even serves as a template in order to assess the submitted projects. During the jury session the key property of "project three" (the opening in the uppermost tier) interacts with the jurors. This interaction picks up more and more speed and develops a dynamic which results in a fundamental destabilisation of the "boiling pot" singularity: its original set of defining properties is manipulated and loses its (persuasive) power. By allowing the solution that "project three" proposes, that is, by modulating the singularity "boiling pot" the jury board explores the space of potential solutions as created by the variety of competition entries. Against this background we argue that experimentation and creativity in architectural competitions can be understood as a tracing of critical points (which we refer to as singularities), and the submitted architectural projects as lines that are mapping out spaces of potential: a 'phase space' (DeLanda, 2002). The sum of the proposed solutions generates a relational space of possible solutions to the problem as outlined in the competition brief. Each proposed solution, that is, each architectural project involves an initial 'judgement': an architect who submits a project tries to anticipate the relations of trade-offs between the interfering fields, which they believe the jury might honour. However, as Chupin (2010) argues, an architectural competition implies three different judgements: the judgements which submitting planners make with regard to what they believe the jury might honour; the judgement of the jury which eventually picks a winner and which unfolds in a relational space as opened up by the projects; and the judgement of the public with regard to the outcome of the competition, which is also, of course, a judgement on both of the prior ones.

Kreiner (2008) showed that the competition brief should not be confused with what will actually be required to win the competition, that is, with those criteria that eventually select the winning project. Put differently, the second 'judgement' - the jury picking a winner - will only experimentally unfold in the interaction with the space as generated by the submitted projects. According to Chupin (2010) this kind of "reflexive" judgement involves a medium and a final object that are interrelated: the final object of the process is defined during the process of judgement. The decisive evaluation criteria thus co-evolve with the examination of the projects that are proposed. The unfolding trajectories of 'what the jury is looking for' may therefore be viewed as a tracing of the singularities of the relational space that is mapped out by the competition entries. As we have shown by means of our vignette some singularities emerge only "piecewise". A jury process can thus be seen as an experimental modulation of singularities and depicts an open process of becoming.

\section{Conclusion}

In the paper at hand we have illustrated the importance of the heterogeneity of perspectives for decision making. We have depicted the heterogeneity of jurors' perspectives as a condition for the modulation of singularities and also how such a modulation can strongly influence a competition's outcome. We have shown that some of the jury's most relevant evaluation and assessment criteria are not given in advance but emerge during the decision-making process as 
a result of the interaction of the diverse component parts that are folded into the architectural competition. One might say that even our described "project three" as such "changed" during the course of the jury assessment sessions as one and the same of its component parts (the opening in the upper tier) has been related to changing images, switching functions and shifting ideas. Following this thought we illustrated that some of the most relevant criteria for judgement and the architectural propositions to be judged co-evolve.

The board of jurors in our sequence of observations managed or dared to explore the space of potential solutions as generated by the submitted architectural propositions. The jury board allowed for a modulation of a singularity that constituted one of its most important tools to evaluate the competition entries. We suggest to regard this act of leaving its certainties behind, that is, the jury's "intrepid" interplay with the competition entries as a characteristic that distinguishes the jury and not to consider it as a weakness in the sense that one accuses the jury of acting randomly or on no solid basis respectively.

Finally we showed that a jury assessment session as we described it should not just be regarded as a collective process in the sense that a number of people is working together towards a solution. Rather, as our observations illustrate, the jurors, the architectural projects in the form of their representations as well as the discourses, images, examples, ideas and 'critical points', which are introduced into the decision making process, define or constitute a situation where the 'collective' must be understood as an assemblage or meshwork of exactly these components and not just of the humans involved.

\section{Acknowledgement}

We would like to acknowledge the Swiss National Science Foundation that funded this research (Funding ID: 100013134906).

\section{References}

Boland, R., \& Collopy, F. (2004). Managing as designing. California: Stanford University Press.

Chia, R. (1997). Thirty years on: From organisational structures to the organisation of thought. Organization Science, 18(4), 685-707.

Chupin, J. P. (2010). Analogie et Theorie en Architecture. Gollion: Infolio.

DeLanda, M. (2002). Intensive science and virtual philosophy. London: Continuum.

DeLanda, M. (2006). A new philosophy of society. Assemblage theory and social complexity. London, New York: Continuum.

Deleuze, G., \& Guattari, F. (1987). A thousand Plateaus. Capitalism and Schitsophrenia. Minneapolis: University of Minnesota Press.
Gibbons, M., Limoges, C., Nowotny, H., Schwartzman, S., Scott, P., \& Trow, M. (1994). The new production knowledge: The dynamics of science and research in contemporary societies. London: Sage.

Gilbert, \& Jormakka, (2005). The willing suspension of disbelief. In Wettbewerb! Competition! (pp. 67-78). Wien: ÖGFA.

Grabher, G. (2004). Temporary architectures of learning: Knowledge governance in project ecologies. Organization Studies, 25(9), 1491-1514.

Grabher, G., \& Maintz, J. (2006). Learning in personal networks: Collaborative knowledge production in virtual forums. Working Papers of the Center on Organizational Innovation. New York City: Columbia University.

Ibert, O. (2007). Towards a geography of knowledge-creation: The ambivalences between 'Knowledge as an Object' and 'Knowing in Practice'. Regional Studies, 41(1), 103-114.

Kamoche, K., \& Cunha, M. P. E. (2004). Improvisation, knowledge and the challenge of appropriation. CIMOC Working Paper Series, 1/ 2004.

Kohoutek, R. (2005). Der unmögliche Wettbewerb. In Wettbewerb! Competition! (pp. 124-129). Wien: ÖGFA.

Kreiner, K. (2008). Architectural competitions. Empirical observations and strategic implication for architectural firms. Unpublished Paper.

Latour, B. (1987). Science in action: How to follow scientists and engineers through society. Cambridge, MA: Harvard University Press.

Latour, B., \& Woolgar, S. (1979). Laboratory life: The social construction of scientific facts. Princeton: Princeton University Press.

Latour, B., \& Yaneva, A. (2008). Give me a gun and I will make all buildings move: An ANT's view of architecture. In R. Geiser (Ed.), Explorations in architecture: Teaching, design, research. Basel: Birkhäuser.

Nonaka, I., \& Konno, N. (1998). The concept of "Ba": Building a foundation for knowledge creation. California Management Review, 40(3), 40-54.

Schön, D. A. (1995). The reflective practitioner: How professionals think in action. Aldershot, England: Arena.

Senge, P. (1990). The fifth discipline. New York: Doubleday Books.

Silberberger, J., Van Wezemael, J., Paisiou, S., \& Strebel, I. (2010). Spaces of knowledge creation. Tracing knowing-in-action in jury based sense-making processes. International Journal of Knowledge Based Development, 1(4).

Söderström. (2000). Des images pour agir. Le visuel en urbanisme, Lausanne, Payot, 187.

Tsoukas, H., \& Chia, R. (2002). On organisational becoming: Rethinking organizational change. Organization Science, 13(5), 567-582.

Van Wezemael, J. E. (2008a). The contribution of assemblage theory and minor politics for democratic network governance. Planning Theory, 7(2), 165-185.

Van Wezemael, J. E. (2008b). Knowledge creation in urban development praxis. In S. Baum \& T. Yigitganlar (Eds.), Knowledge-based urban development (pp. 1-20). Hershley: Idea.

Van Wezemael, J. E. (2010). Modulation of singularities - A complexity approach to planning competitions. Aldershot: Ashgate.

Yaneva, A. (2009). The making of a building: A pragmatist approach to architecture. Bern: Peter Lang. 